\title{
Writing in the Wild
}

\section{WRITERS' MOTIVATION IN FAN-BASED}

AFFINITY SPACES

\author{
Jen Scott Curwood, Alecia Marie Magnifico, \& Jayne C. Lammers
}

\section{Digital tools and online spaces offer new opportunities for young people to share their creative work with an authentic audience.}

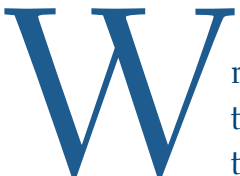

riting is increasingly digital and multimodal. Writers, their practices, and their tools have never existed in a vacuum, but technology offers new spaces for writers to respond to the world around them and readily share their work with readers. Although school environments treat cognition as an individual accomplishment, real-world "in the wild" learning tasks are intertwined with culture, available resources, and interaction with others (Hutchins, 1995). Today's technologies have forged new ways that young people can engage with words and ideas. When they post a status update on Facebook, share a story on FanFiction. net, or role-play on Tumblr, their writing practices are inextricably linked to digital tools and online spaces. These, in turn, shape their understanding of audience, purpose, and genre.

In this article, we draw from three ethnographic studies of adolescent literacy and online affinity spaces related to The Hunger Games, Neopets, and The Sims

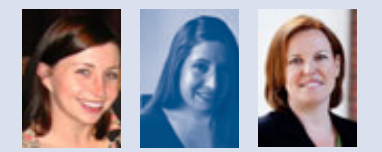

Authors (left to right) Jen Scott Curwood is a lecturer at the University of Sydney, Australia; e-mail js.curwood@sydney.edu.au.

Alecia Marie Magnifico is a post doctoral fellow at the University of Illinois at Urbana-Champaign, USA e-mail amagnif@illinois.edu.

Jayne C. Lammers is an assistant professor at the University of Rochester, New York, USA; e-mail jlammers@warner.rochester.edu.
(Curwood, 2013a; Lammers, 2012; Magnifico, 2012). By actively participating in affinity spaces around a shared passion (Gee, 2004), young people can easily access an authentic audience who reads, responds to, and even critiques their written work. Within these spaces, youths create and share transformative works, which describe the kinds of writing and designing practices that take an original artifact and turn it into something with a new function or expression. This process includes, but is not limited to, fan-inspired stories, artwork, videos, and games; these involve a variety of modes and semiotic resources.

As literacy researchers, teacher educators, and former classroom teachers, we are interested in understanding the links among writing, motivation, and fan culture. We argue that the contemporary tools and spaces for writing that are available to youths are essential for their achievement and engagement. Prior scholarship indicates that young people who feel confident in their abilities are much more motivated than their peers in terms of their effort, persistence, and behavior (Pintrich \& Schunk, 2002). Research on motivation, in particular, examines "what gets individuals moving (energization) and toward what activities or tasks (direction)" (Pintrich, 2003, p. 669). This leads us to ask: What moves young people toward producing and sharing their writing within online affinity spaces? 


\section{Fan-Based Writing Practices}

Research by the Pew Internet and American Life Project indicates that $80 \%$ of adolescents use online social network sites, $38 \%$ share original creative work online, and $21 \%$ remix their own transformative works, inspired by others' words and images (Lenhart, Ling, Campbell, \& Purcell, 2010; Lenhart et al., 2011). As a result of greater accessibility and affordability of Internet-connected devices, young people are increasingly using online spaces to collaborate and communicate. More than that, they see these spaces as a way to share their writing in both in- and out-of-school contexts. The way in which youths critically engage with digital tools and transformative works is particularly evident in fan-based communities. Our ethnographic research suggests that fan culture can support the literacy practices inherent in writing stories, creating art, producing songs, and participating in role-playing games.

Prior studies indicate that online affinity spaces provide ways for fans to write, edit, design, and review transformative works (Black, 2008; Chandler-Olcott \& Mahar, 2003; Thomas, 2007). We posit that these spaces motivate young people to write through selfdirected and interest-based opportunities to share their work with an authentic audience. However, we also acknowledge that contemporary research often focuses on the exceptional cases; namely, the 1 in 5 young people who are creating and distributing transformative works in online spaces. We argue that much can be learned from ethnographic research of these exceptions when extrapolated to the students in each of our classrooms.

For instance, a recent study by Lunsford and colleagues (2008) found that today's students are writing more, and they are highly effective at crafting messages for a particular audience. More than a third of students' writing took place outside school, and much of it occurred online. Buck (2012) adds that it is imperative for educators to value students' outof-school writing in online spaces and understand how these experiences contribute to their academic writing.

\section{Young people are increasingly using online spaces to collaborate and communicate.}

\section{Writing and Motivation Within an Affinity Space Framework}

In understanding literacy from a sociocultural perspective, it is impossible to separate literacy practices from their social, cultural, political, historical, and temporal contexts. Lankshear and Knobel (2006) defined literacies as "socially recognized ways of generating, communicating, and negotiating meaningful content through the medium of encoded texts within contexts of participating in Discourses" (p. 64).

In this light, digitally mediated practices, such as writing fan fiction, remixing videos, playing videogames, modifying wikis, and creating podcasts, are designed literacy practices (New London Group, 1996). Rather than being static, linear, individually created, and print based, these texts are fluid, dynamic, nonlinear, and often collaboratively constructed. Moreover, to engage in meaning-making activities with these texts, individuals must simultaneously read a variety of modes of representation (Kress \& van Leeuwen, 2001), which may occur in diverse spatial contexts (Leander, 2007).

According to Gee (2004), affinity spaces are sites of informal learning where "newbies and masters and everyone else" interact around a shared passion (p. 85). These spaces often spread across many sites, including face-to-face meetings, message boards, blogs, and websites. We use Gee's term portals to conceptualize the numerous connected entry points to the affinity spaces related to The Hunger Games, Neopets, and The Sims. Portals offer multiple interest-driven trajectories, opportunities to learn with others, and paths toward becoming a participant (Squire, 2011). Though the field continues to theorize affinity spaces (Hayes \& Duncan, 2012), we recognize a need for greater attention to the nature of learning, doing, and being in online affinity spaces.

In our recent work (Lammers, Curwood, \& Magnifico, 2012), we argued that an update to Gee's (2004) initial categorization of online affinity spaces was necessary, and we proposed that contemporary affinity spaces have nine defining features:

1. A common endeavor is primary.

2. Participation is self-directed, multifaceted, and dynamic.

3. Portals are often multimodal.

4. Affinity spaces provide a passionate, public audience for content. 
5. Socializing plays an important role in affinity space participation.

6. Leadership roles vary within and among portals.

7. Knowledge is distributed across the entire affinity space.

8. Many portals place a high value on cataloguing content and documenting practices.

9. Affinity spaces encompass a variety of mediaspecific and social networking portals.

To understand the writing practices that populate these contexts, we take a sociocultural, situated approach by observing and participating in affinity spaces. This perspective leads us to examine how these spaces structure writing practices for young people, and how they mentor novice members into full participation, because it is through this mentorship that learning occurs. Where classrooms often expect one individual - the teacher - to accomplish this kind of enculturation, most affinity spaces design leadership and mentorship that is distributed across many individuals, texts, and tools (Gomez, Schieble, Curwood, \& Hassett, 2010).

Examining participation from a sociocultural and situated approach is particularly useful because it highlights the multiple opportunities for interactions with audience members. Even if many affinity space members may never meet face to face, online interactions provide opportunities for literacy learning through tool use, collaboration, and critique (Steinkuehler, 2007). Affinity spaces often revolve around sharing transformative works with other participants, who serve as an active and interactive audience for these creations. Writers' ideas about and goals for their own work change in response to the formative feedback they receive from readers (Beach \& Friedrich, 2006; Beason, 1993; Magnifico, 2010).

When young writers believe in their own selfefficacy, self-concept, competence, and selfregulation, they are able to set more effective goals and improve their "will to write" (Boscolo \& Hidi, 2007, p. 2). In other words, their beliefs in themselves and their writing abilities are malleable and can be influenced by their topic, genre, and feedback from readers. Lipstein and Renninger (2007) found that when teachers gave feedback on how writing might be more effective for readers, students more readily maintained their interest in writing. This echoes
Lenhart, Arafeh, Smith, and Macgill's (2008) finding that teens are motivated to write by the topic's perceived relevance to their lives and their words' potential to make an impact on their communities.

\section{Methods}

We have conducted ethnographic studies of three online affinity spaces: The Hunger Games, Neopets, and The Sims. In each of these spaces, young adults created transformative works associated with the specific fan culture. Each study had between 8 and 20 focal participants, who ranged in age from 11 to 23 . Participants in these studies represented a variety of countries, including the United States, the United Kingdom, Canada, and Australia.

\section{Research Contexts}

The Hunger Games. The Hunger Games is part of a growing number of dystopian novels written for young adults. From 2008 to 2012, Suzanne Collins's trilogy sold more than 50 million copies worldwide. The novel is set in a postapocalyptic world, where the country of Panem has an affluent ruling city called the Capitol, which is surrounded by thirteen impoverished districts. In the Dark Days, the districts rose up against the Capitol. To remind the citizens of Panem that such a revolution must never happen again, each year the Capitol subjects the districts to the Hunger Games. The protagonist, 16-year-old Katniss Everdeen, must fight for her survival. Curwood's (2013a; 2013b) two-year study examined fan practices in various portals where they write fan fiction, create art, produce videos, compose music, and design roleplaying games.

Neopets. Neopets is a Web-based game in which players care for virtual pets. A massively multiplayer site constructed from webpages, message boards, and flash plug-ins, Neopets boasts more than 250 million created pets. Magnifico's (2012) one-year study examined many aspects of Neopets play and shows that common player activities include engagement with official site content, such as virtual item collections and flash games, but also personal creation, including graphic design, webpage coding, writing, and art making. This study focused on Neopian writers, exploring why they create writing and art about their Neopets, how they choose publication venues for this work, and how they craft and revise their work. 
The Sims. The Sims series of videogames is the most popular PC game of all time, with more than 150 million copies sold worldwide. A life-simulation game, The Sims invites players to create families, build communities, and interact in an open-ended game space. In a two-year study of The Sims affinity space, Lammers (2011) examined a particular portal for Sims fan fiction writers, The Sims Writers' Hangout ( $\mathrm{SWH}$ ). An online discussion forum, $\mathrm{SWH}$ had more than 12,000 members who had contributed over 665,000 posts as of May 2010. Lammers's (2012, 2013) research explored the nature of tensions exhibited within this portal and the pedagogic discourse used to teach expectations and create the official knowledge of $\mathrm{SWH}$.

\section{Affinity Space Ethnography}

Our individual data collection began with systematic observation (Androutsopoulos, 2008) to gain insight into the dynamics of communication and semiotic production in each online affinity space. We conducted multiple interviews with each focal participant via Skype, e-mail, or private messages. These interviews sought information about the factors that shaped their literacy practices, participation in online affinity spaces, and engagement with The Hunger Games, Neopets, and The Sims. We also collected artifacts, including fan-based transformative works, discussion board rules, and online profiles.

We then collectively conducted descriptive case analysis (Yin, 2003), creating case studies from focal participants in each affinity space. Using a thematic analysis framework (Boyatzis, 1998; Saldaña, 2009) to perform repeated rounds of qualitative coding, we examined these adolescents' goals and motivations to gain insight into what moved them to produce and share their writing in fan-based affinity spaces. Our analysis involved gradually consolidating and refining participants' discussions of their literacy practices into broad patterns. We considered how young people describe their motivation to write, how their work demonstrates their goals, and how affinity spaces function to support their writing practices.

$$
\begin{aligned}
& \text { Young people engage in self- } \\
& \text { sponsored, multigenre writing, } \\
& \text { shaped by their real and imagined }
\end{aligned}
$$

\section{Results and Discussion}

In this section, we focus on three specific characteristics of online affinity spaces related to participation, audience, and multimodal composition and consider how these features shape young adults' writing practices. We are interested in how affinity spaces related to The Hunger Games, Neopets, and The Sims provide young people with authentic writing opportunities. Rather than offer broad findings from our three ethnographic studies, we instead highlight three young adults who are avid writers within their respective fan spaces. Cassie, Sheena, and Eve (all names are pseudonyms) engage in a variety of writing and designing practices.

\section{Participation Is Self-Directed, Multifaceted, and Dynamic}

Young people within The Hunger Games affinity space have multiple opportunities for participation, communication, and collaboration. Some fans may gravitate toward writing fan fiction and making fan videos, and others may opt to design role-playing games and manage fansites. Affinity spaces allow for multiple and self-directed forms of participation, which can range from active involvement to legitimate peripheral participation (Lave \& Wenger, 1991).

As fans gain social and cultural capital within the affinity space, they often take on more participatory roles within and across portals. Black and Steinkuehler's (2009) research found that online affinity spaces foster the development of core literacy practices. Although these practices may take place in out-of-school settings, they reflect the ways in which literacy is conceptualized within national education policies and valued within content standards. In particular, literacy involves the ability to make meaning across multiple modes, semiotic resources, and digital tools.

Curwood's (2013a; 2013b) study of The Hunger Games fan culture shows how young people engage in self-sponsored, multigenre writing as well as how their writing process is shaped by their real and imagined audience. Cassie offers insight into participation within the fandom. At the suggestion of her middle school librarian, Cassie read The Hunger Games and was captivated by the dystopian world of Panem. To discuss the novels with others, she turned to the Internet. After Cassie discovered the rapidly growing Hunger Games fandom, she took on an active role within the community.

Cassie, now 16 years old and a high school student in New Hampshire, is a moderator of one 
popular fansite. Within that role, she writes news stories, shares transformative works, reviews books, and contributes to the Twitter feed. To date, the website has had more than 6 million visits and the Twitter account has 52,000 followers. In addition to her involvement on the fansite, she has acted in a popular fan video, participated in the Fireside Chat podcast, and written a fan fiction story for the Potter Games, an online choose-your-own adventure story collection.

Cassie has chosen to take on an active role by managing a portal within the affinity space, whereas other fans may share their transformative works, participate in online discussions, or simply lurk as passive participants. Consequently, the nature of affinity spaces allows for self-directed participation. Cassie explains that the online Hunger Games fandom has changed her understanding of the trilogy because "it allowed me to explore perspectives other than my own, and I see more of the world that the author has created."

As a writer, Cassie found that the affinity space offered her the opportunity to hone her craft. She elaborates, "I've written informatively and creatively in school before, and I have been able to use both as vehicles to help me spread my love for reading The Hunger Games." For that reason, the majority of Cassie's writing within the fandom involves sharing information with other fans; her aim is to prompt them to deepen their understanding of the trilogy through her blog posts, quiz questions, and tweets.

Cassie's writing is fueled by both The Hunger Games novels and her ever-growing audience. "My motivation for posting informatively on HungerGamesTrilogy.net is knowing that there are some neat pieces of news, or cool fan art, or other really great information that fans would want to know," she says. "By placing it on our website, we are making it easier for fans to access and we are promoting their passion for the book series." For Cassie, her reading and writing practices are interrelated. Like many other fans, her enthusiasm for The Hunger Games bleeds over into the rest of her life.

For example, she was completing a reading for her history class and came across the word tribute. It immediately brought to mind the tributes in the Hunger Games, and she tweeted about it, using the hashtag \#HungerGamesProblems. Within seconds, other fans picked up on the new hashtag. The dynamics of social media encouraged Cassie and other fans to share her intertextual connections. Cassie adds, "Twitter gives me the chance to connect with people in the fandom that I may not have interacted with otherwise, and it begins a lot of interesting debates and conversations with fans." The self-directed, multifaceted, and dynamic nature of the online affinity space provides Cassie with tools to share her love of reading and engage in authentic writing practices.

\section{Affinity Spaces Provide a Passionate, Public Audience for Content}

Many adolescents who participate in affinity spaces cite the availability of readers as a reason for their engagement. Magnifico's (2012) study of writers for the Neopian Times (NT), the Neopets weekly site newspaper, found that available audiences, site contests, and achievements motivate players to create transformative works about their pets and game experiences. Many Neopian writers aim to win game achievements by writing for publications like the NT, and others narrativize their play, crafting stories about themselves and their adopted pets. This personal writing is loosely structured, multimodal, and presented across social network-like pages, whereas publication pieces are submitted to editors and crafted to conform to specific genre requirements.

Sheena, a Neopets player who grew up in Singapore and Canada and a 19-year-old college student during the study, started playing at age 10 and became an NT writer at 16. Sheena's writing includes individual and collaborative NT pieces, poetry and storytelling contest entries and profile pages describing herself and her pets. Sheena describes writing for the NT and submitting to site contests to win achievements and Neopoints, but also for "friendship and feedback" from other players. "Online...I came to see myself as part of an exchange, on par with other writers, regardless of age."

Magnifico (2012) described two kinds of Neopian writing, presented for two audiences. The first kind describes players' activities, pets, and identities through multimodal compositions that provide narrative glue for players' experiences-how they understand and portray their play. For example, Sheena's pet profiles chronicle her pets' maturation over time. One of her pets changes forms through several NT stories and art gallery entries, "but she remains the same individual-it's just a growing-up process." Such histories make players' ideas and goals legible to the often amorphous audience of other Neopians. In a game where no central activities or quests exist, these multimodal pastiches share, record, and trace their play over time.

Beyond this social narrative building, Sheena enjoys Neopets writing because of the "instant feedback." She submits her writing to site publications 
like the NT, the Storytelling Contest, and the Poetry Contest, whose editors manage submissions and accept pieces that conform to particular genre requirements. Although Sheena has written for many venues, "NT writing was the most rewarding because of the direct feedback."

When submitting to these publications, players receive results (and sometimes prizes) quickly, and readers often send reactions and congratulations, making passionate Neopians visible. Sheena described saving these "fan mails," contributing to a "guild" group of NT writers, and participating in an NT community where in-depth criticism provided further motivation. As she puts it, these writing groups give "more detailed critiques, though, not just praise.... It's important to understand how your readers are receiving your words."

For writers like Sheena who create consistent pet characters, these two kinds of writing-social narrative and editor-mediated publication - come together. When Sheena was planning a collaborative NT piece with another writer, Kay, their discussion voiced practical considerations as well as narrative ones:

Sheena: So far there's only been 2 articles about pet fostering. Do you want to do that topic? I've just begun to foster pets.

Kay: By fostering pets do you mean adopting them, labbing them, and then adopting them out again? Because I do that all the time.

Sheena: Exactly. Both the articles that have been published on fostering are from the owners' points of view....Want to do one from our pets' point of view? How they feel about taking in an abandoned pet, seeing the pet transform, and then saying goodbye.

Kay: YES!...[and] I'd love to try it in a darker voice. Perhaps I would write from Nelari, my Pteri...? She's had tons of pets come and go from that account so it would make "sense," I suppose!

In this excerpt, Sheena first considers an uncommon story topic, hoping that this strategy-appealing to NT editors' needs for new material-will lead to publication. But Kay invokes her pet's "voice," wondering if a fostering story might be "darker," and thus better suited to characters with complex experiences. When Kay mentions "sense," she means that her pets' experiences are fictional and, thus, malleable. Yet herself and, presumably, for her readers who become invested in these stories as well.

Although it might initially seem that players who write for the NT and enter site contests respond to external motivations of prizes and achievements, many writers' goals are more complicated. Intertwined with maintaining their own stories, Sheena and other Neopian writers describe ultimately seeking an audience for their ideas.

\section{Affinity Space Portals Are Often Multimodal}

In many online fan-based affinity spaces, adolescents produce multimodal transformative works, including websites, avatars, blogs, videos, maps, and podcasts, to demonstrate their media fandom. Lammers's (2011) analysis of The Sims Writers' Hangout (SWH) uncovered that young people engage in multimodal literacies, creating member profiles and designing banners to advertise their current fan fiction stories. Designing multimodal transformative works can be a motivating endeavor for writers because "in multimodal ensembles...the possibilities of supplementing messages with meaning multiply, and incorporate the demands and the potentials of imagination of all the modes involved" (Kress, 2003, p. 170). Eve exemplifies how the multimodal nature of affinity space portals and practices can serve to motivate a young person to engage in imaginative fan-based writing.

As a 13-year-old, Eve had an interest in architecture and interior design that led her to begin playing The Sims because "it was a thousand times better than LEGOs." A decade later, working in an elementary after-school-care program in Hawaii, Eve still created Sims-related transformative works and reflected on how her Sims writing evolved during interviews. When The Sims 2 was released and fans began posting Sims fan fiction online, she became interested in reading the stories. Reading turned into writing when she graduated from high school: "That's when my love for writing and photography grew intense and I figured I had a knack for getting lost in these new worlds I created."

In the years that followed, Eve became a popular author on SWH, publishing two Sims fan fiction series while developing an expertise in digital image editing. Eve also participated in other portals within the Sims affinity space, promoting her Sims-related transformative works through Twitter, YouTube, and her website. The multimodal nature of the Sims affinity space motivated Eve in two key ways: It provided a means for expressing creativity, and it helped 
her develop confidence as a writer, despite her dyslexia.

Expressing creativity motivates much of Eve's participation in the Sims affinity space. As a means of reflecting on the teenage experience and channeling her passion for acting, Eve's most popular Sims fan fiction series was a story that explored relationships as a college student vies for her dream part in a school production of Hamlet. Over the course of two years, Eve posted seven chapters in the series and interacted with readers in a forum thread on $\mathrm{SWH}$. She received a great deal of reader praise for the images in her story. The one shown in the Figure was specifically commented on by a reader who said, "This is my favorite pic. Just gorgeous! I love the background.”

Eve's interest in visual modes of expression with The Sims led her to create Sims videos, which she found "fascinating because there's the story, music, and animated emotional side to it....What motivates me to create videos these days is my passion of expressing my creativity, also my friends/fans support and encouragement." The evolution of Eve's Sims-related transformative works was fueled, in part, by her interest in expressing her creativity, and the multimodal design available to her within the Sims affinity space proved to be highly motivating for this young woman.

The multimodal nature of participation in Sims affinity space portals also motivated Eve because it allowed her to develop confidence as a writer in ways not available to her in traditional school settings. Eve explained, "When I was in high school, I had a serious problem with dyslexia; it made me feel slow and unwise whenever I read or wrote things for school." In the Sims affinity space, Eve received encouragement from readers of her stories and developed multimodal

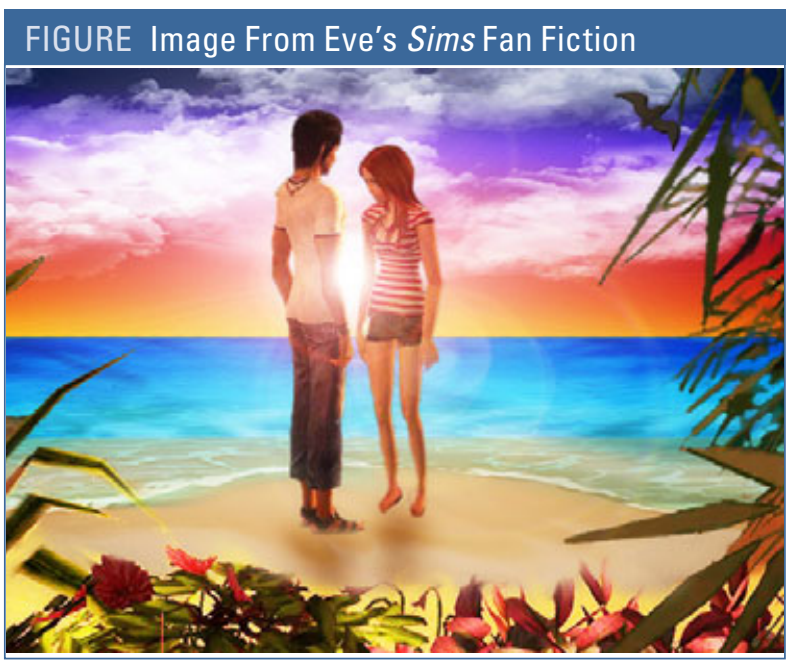

literacy expertise valued by the participants: "I love the whole storyline you've got going, the photography is wonderful and it's well written."

Eve created story covers for those who requested her assistance and also wrote tutorials, one about photo editing and one about writing, to share her knowledge with others in SWH. "Funny how things change....Even though I still have dyslexia, I've come to understand how to overcome that depressing emotion and become more comfortable and confident with reading and writing as I do more of both each week." For Eve, the Sims affinity space led to her development as a writer by encouraging her use of multimodal literacy practices.

\section{Implications for Teaching Writing}

Alvermann (2008) asks, "What drives young people to create online content? How unique is the culture of online literacies? Do adolescents' online literacies have implications for the research and teaching of literacy?" (p. 9). Not only do these questions highlight how online literacies shape identities and practices, but we also believe that they have significant implications for young adults' achievement and engagement in school-based learning. This leads us to ask: How can research on adolescent writing in online affinity spaces shape teachers' writing pedagogy? Our ethnographic research on fan-based writing communities shows that youths thrive when given the chance to draw on multiple genres and diverse modes in their writing.

In this article, we have considered what motivates young adults to produce and share their writing. At the outset, we acknowledged that these three participants could be considered exceptional cases. Even if data from the Pew Research Center indicate that one in five adolescents share their transformative works online, Cassie, Sheena, and Eve demonstrate an incredible level of commitment to their respective fandom. However, we think that it is imperative for researchers to theorize adolescents' online literacies at the same time that educators incorporate adolescents' online literacies into everyday classroom practices.

We suggest that teachers attune to the practices rather than the specific content of the affinity spaces described here. In other words, teachers should not seek to coopt popular culture, but they can allow writers the space to remix and transform others' work, build portfolios that demonstrate their developing writing skills, and share their writing with an authentic audience. Popular culture, in this sense, may be 
a springboard for students' ideas and interests. For instance, students can use Minecraft to construct the Globe Theater, watch a Simpsons clip to understand literary techniques, and draw inspiration from FanFiction.net to write an alternative ending for Wuthering Heights.

Making space for interpretive and interactive work that is similar to online activities may help students begin to make and extend connections with in-school texts. Creating a digital story or an interactive poster might help students to use summary and synthesis skills, and they may engage those students who typically shy away from school tasks (Curwood \& Cowell, 2011). Moreover, asking students to write stories, review others' work, and revise their own texts could help them understand that writing can be used for the active communication of their ideas (Beach \& Friedrich, 2006; Beason, 1993).

\section{Take Action}

STEPS FOR IMMEDIATE IMPLEMENTATION

$\checkmark$ Design a survey and ask students about their experiences with fan culture and online communities. Inquire about their reading and writing practices in out-of-school contexts and then create literacy learning activities to connect with these experiences.

$\checkmark$ Expand the boundaries of your classroom by incorporating an online space, such as Ning or Scholar. In this space, you can model the peerreview process for your students, both during an in-class workshop and an online demonstration. They can then share their writing and offer constructive feedback to others.

$\checkmark$ Encourage students to engage in collaborative and multimodal responses. For example, students can create a podcast in which they take on the perspective of a specific character and react to key events or they create a glog that explores composers or themes. Alternatively, students can use a video game engine to create machinima based on classroom texts.

$\checkmark$ Online affinity spaces depend on technology, but teachers can create affinity spaces within the physical environment, too. For instance, teachers can draw on workshop-based approaches to student writing and share this work with a wide audience by creating a gallery, holding a poetry slam, or crafting a literary magazine.
Our research suggests that, instead of taking young people away from literature and literacy, online spaces and digital tools can motivate students in new and complex ways to engage with reading, writing, and designing.

Our field needs to move beyond focusing on young adults' new literacy practices in the wild, or in informal out-of-school spaces, to articulate how teachers can design for new literacies in school-based settings. All too often, technology creates a digital divide across students, teachers, and schools. If young people have self-directed, multimodal, and authentic writing opportunities in out-of-school settings, this divide will only widen. If our goal is to prepare students for the 21st century, then we need to consider what we can learn from the kinds of writing experiences that today's youths have in online affinity spaces. This article is a first step to describe young adults' writing practices in fan-based online affinity spaces and to suggest how these practices can be incorporated into school-based learning.

\section{References}

Alvermann, D.E. (2008). Why bother theorizing adolescents' online literacies for classroom practice and research? Journal of Adolescent \& Adult Literacy, 52(1), 8-19. doi:10.1598/ JAAL.52.1.2

Androutsopoulos, J. (2008). Potentials and limitations of discourse-centered online ethnography. Retrieved January 15, 2013, from www.languageatinternet.org/articles/2008/1610

Beach, R., \& Friedrich, T. (2006). Response to writing. In C.A. MacArthur, S. Graham, \& J. Fitzgerald (Eds.), Handbook of writing research (pp. 222-234). New York: Guilford.

Beason, L. (1993). Feedback and revision in writing across the curriculum classes. Research in the Teaching of English, 27(4), 395-422.

Black, R.W. (2008). Adolescents and online fan fiction. New York: Peter Lang.

Black, R.W., \& Steinkuehler, C. (2009). Literacy in virtual worlds. In L. Christenbury, R. Bomer, \& P. Smagorinsky (Eds.), Handbook of adolescent literacy research (pp. 271-286). New York: Guilford.

Boscolo, P., \& Hidi, S. (2007). The multiple meanings of motivation to write. In G. Rijlaarsdam (Series Ed.), P. Boscolo, \& S. Hidi (Vol. Eds.), Studies in writing: Vol. 19. Writing and motivation (pp. 1-14). Oxford: Elsevier.

Boyatzis, R.E. (1998). Transforming qualitative information: Thematic analysis and code development. Thousand Oaks, CA: Sage.

Buck, A. (2012). Examining digital literacy practices on social network sites. Research in the Teaching of English, 47(1), 9-38.

Chandler-Olcott, K., \& Mahar, D. (2003). Adolescents' anime-inspired "fanfictions": An exploration of multiliteracies. Journal of Adolescent 6 Adult Literacy, 46(7), 556-566. 
Curwood, J.S. (2013a). The Hunger Games: Literature, literacy, and online affinity spaces. Language Arts, 90(6).

Curwood, J.S. (2013b). Fan fiction, remix culture, and the Potter Games. In V.E. Frankel (Ed.), Teaching with Harry Potter (pp. 81-92). Jefferson, NC: McFarland.

Curwood, J.S., \& Cowell, L.L. (2011). iPoetry: Creating space for new literacies in the English curriculum. Journal of Adolescent \& Adult Literacy, 55(2), 110-120. doi:10.1002/ JAAL.00014

Gee, J.P. (2004). Situated language and learning: A critique of traditional schooling. New York: Routledge.

Gomez, M.L., Schieble, M.B., Curwood, J.S., \& Hassett, D.D. (2010). Technology, learning, and instruction: Distributed cognition in the secondary English classroom. Literacy, 44(1), 20-27. doi:10.1111/j.1741-4369.2010.0054l.x

Hayes, E.R., \& Duncan, S.C. (2012). Learning in video game affinity spaces. New York: Peter Lang.

Hutchins, E. (1995). Cognition in the wild. Cambridge, MA: MIT University Press.

Kress, G. (2003). Literacy in the new media age. New York: Routledge. doi:10.4324/9780203164754

Kress, G., \& van Leeuwen, T. (2001). Multimodal discourse: The modes and media of contemporary communication. London: Hodder Arnold.

Lammers, J.C. (2011). "The Hangout was serious business": Exploring literacies and learning in an online Sims fan fiction community. (Unpublished doctoral dissertation). Arizona State University, Tempe.

Lammers, J.C. (2012). "Is the Hangout...the Hangout?”: Exploring tensions in an online gaming-related fan site. In E.R. Hayes \& S.C. Duncan (Eds.), Learning in video game affinity spaces (pp. 23-50). New York: Peter Lang.

Lammers, J.C. (2013). Fan girls as teachers: Examining pedagogic discourse in an online fan site. Learning, Media and Technology. doi:10.1080/17439884.2013.764895.

Lammers, J.C., Curwood, J.S., \& Magnifico, A.M. (2012). Toward an affinity space methodology: Considerations for literacy research. English Teaching: Practice and Critique, 11(2), $44-58$.

Lankshear, C., \& Knobel, M. (2006). New literacies: Everyday practices and classroom learning. New York: Open University Press.

Lave, J., \& Wenger, E. (1991). Situated learning: Legitimate peripheral participation. Cambridge, UK: Cambridge University Press. doi:10.1017/CBO9780511815355

Leander, K.M. (2007). "You won't be needing your laptops today": Wired bodies in the wireless classroom. In C. Lankshear \& M. Knobel (Eds.), A new literacies sampler (pp. 25-48). New York: Peter Lang.

Lenhart, A., Arafeh, S., Smith, A., \& Macgill, A. (2008). Writing, technology, and teens. Pew Internet and the American Life Project. Retrieved January 15, 2013, from www.pewinternet .org

Lenhart, A., Ling, R., Campbell, S., \& Purcell, K. (2010). Teens and mobile phones. Pew Internet and the American Life Project. Retrieved January 15, 2013, from www.pewinternet .org

Lenhart, A., Madden, M., Smith, A., Purcell, K., Zickuhr, K., \& Rainie, L. (2011). Teens, kindness, and cruelty on social network sites. Pew Internet and the American Life Project. Retrieved January 15, 2013 from www.pewinternet.org

Lipstein, R.L., \& Renninger, K.A. (2007). Putting things into words: The development of 12-15-year-old students' interest for writing. In G. Rijlaarsdam (Series Ed.), P. Boscolo, \& S. Hidi (Vol. Eds.), Studies in writing: Vol. 19. Writing and motivation (pp. 113-140). Oxford: Elsevier.

Lunsford, A.A., Stapleton, L., Fishman, J., Krampetz, E., Rogers, P.M., Diogenes, M., \& Otuteye, M.. (2008). Stanford study of writing. Retrieved January 15, 2013, from ssw.stanford.edu/ research/research.php

Magnifico, A.M. (2010). Writing for whom: Cognition, motivation, and a writer's audience. Educational Psychologist, 45(3), 167-184. doi:10.1080/00461520.2010.493470

Magnifico, A.M. (2012). The game of neopian writing. In E.R. Hayes \& S.C. Duncan (Eds.), Learning in videogame affinity spaces (pp. 212-234). New York: Peter Lang.

New London Group. (1996). A pedagogy of multiliteracies: Designing social futures. Harvard Educational Review, 66(1), 60-92.

Pintrich, P.R. (2003). A motivational science perspective on the role of student motivation in learning and teaching contexts. Journal of Educational Psychology, 95(4), 667-686. doi:10.1037/0022-0663.95.4.667

Pintrich, P.R., \& Schunk, D.H. (2002). Motivation in education: Theory, research, and applications. Upper Saddle River, NJ: Prentice-Hall.

Saldaña, J. (2009). The coding manual for qualitative researchers. Thousand Oaks, CA: Sage.

Squire, K. (2011). Video games and learning: Teaching and participatory culture in the digital age. New York: Teachers College Press.

Steinkuehler, C.A. (2007). Massively multiplayer online games as a constellation of literacy practices. E-learning, 4(3), 297-318. doi:10.2304/elea.2007.4.3.297

Thomas, A. (2007). Youth online: Identity and literacy in the digital age. New York: Peter Lang.

Yin, R.K. (2003). Case study research: Design and methods. Thousand Oaks, CA: Sage.

\section{More to Explore}

\section{CONNECTED CONTENT-BASED RESOURCES}

WEBSITES FEATURING FAN-CREATED CONTENT

- Hunger Games Trilogy: www.hungergamestrilogy.net/

- The Neopian Times: www.neopets.com/ntimes/

- The Sims 3 Exchange: www.thesims3.com/ moviesandmore/

- FanFiction.net: www.fanfiction.net

\section{BOOKS}

- Beach, R., Thein, A. H., \& Webb, A. (2012). Teaching to exceed the English language arts Common Core State Standards: A literacy practices approach for 6-12 classrooms. New York: Routledge.

- Hayes, E.R. and Duncan, S.C. (2012). Learning in video game affinity spaces. New York: Peter Lang. 